\title{
Increased isolation of nontuberculous mycobacteria among TB suspects in Northeastern, Tanzania: public health and diagnostic implications for control programmes
}

\author{
Abubakar S. Hoza ${ }^{1,2^{*}}$, Sayoki G. M. Mfinanga ${ }^{3}$, Arne C. Rodloff ${ }^{1}$, Irmgard Moser ${ }^{4}$ and Brigitte König ${ }^{1}$
}

\begin{abstract}
Background: Non-tuberculous mycobacteria (NTM) are increasingly reported worldwide associated with human disease. Defining the significance of NTM in settings with endemic tuberculosis (TB) requires the discrimination of NTM from TB in suspect patients. Correct and timely identification of NTM will impact both therapy and epidemiology of TB and TB-like diseases. The present study aimed at determining the frequency and diversity of NTM among TB suspects in northeastern Tanzania.

Methods: A cross-sectional study was conducted between November 2012 through January 2013. Seven hundred and forty-four sputum samples were collected from 372 TB suspects. Detection was done by using phenotypic, GenoType ${ }^{\circledR}$ Mycobacterium CM/AS kits, $16 \mathrm{~S}$ rRNA and hsp65 gene sequencing for identification of isolates not identified by Hain kits. Binary regression model was used to analyse the predictors of NTM detection.

Results: The prevalence of NTM was $9.7 \%$ of the mycobacterial isolates. Out of 36 patients with confirmed NTM infection, 12 were HIV infected with HIV being a significant predictor of NTM detection $(P<0.001)$. Co-infection with Mycobacterium tuberculosis ( $M$. tb) was found in five patients. Twenty-eight NTM isolates were identified using GenoType ${ }^{\circledR}$ Mycobacterium CM/AS and eight isolates could not be identified. Identified species included M. gordonae and M. interjectum 6 (16.7\%), M. intracelullare 4 (11.1\%), M. avium spp. and M. fortuitum 2 (5.5\%), M. kansasii, M. lentiflavum, M. simiae, M. celatum, M. marinum 1 (2.8\%) each. Of isolates not identified to subspecies level, we identified M. kumamotonense (2), M. intracellulare/kansasii, M. intermedium/triplex, M. acapulcensis/flavescens, M. stomatepiae, M. colombiense and $M$. terrae complex (1) each using 16S rRNA sequencing. Additionally, hsp65 gene sequencing identified $M$. kumamotonense, M. scrofulaceum/M. avium, M. avium, M. flavescens/novocastrense, M. kumamotonense/hiberniae, M. lentiflavum, M. colombiense/M. avium and M. kumamotonense/terrae/hiberniae (1) each. Results of the 16S rRNA and hsp65 gene sequencing were concordant in three and discordant in five isolates not identified by GenoType ${ }^{\circledR}$ Mycobacterium CM/AS.
\end{abstract}

\footnotetext{
*Correspondence: abshoza@gmail.com

${ }^{1}$ Institute of Medical Microbiology and Epidemiology of Infectious

Diseases, University of Leipzig, Liebigstrasse 21,04103 Leipzig, Germany

Full list of author information is available at the end of the article
} 
Conclusion: NTM infections may play a vital role in causing lung disease and impact management of TB in endemic settings. GenoType ${ }^{\circledR}$ Mycobacterium CM/AS represents a useful tool to identify clinical NTM infections. However, $16 \mathrm{~S}$ rRNA gene sequencing should be thought for confirmatory diagnosis of the clinical isolates. Due to the complexity and inconsistence of NTM identification, we recommend diagnosis of NTM infections be centralized by strengthening and setting up quality national and regional infrastructure.

Keywords: Nontuberculous mycobacteria, Peripheral diagnostic centres, Human immunodeficiency virus (HIV), Tanzania

\section{Background}

Over the past decades, the prevalence of pulmonary nontuberculous mycobacteria (NTM) is increasingly reported worldwide. However, epidemiological and surveillance data of NTM infections are still limited [1]. Defining the epidemiology of NTM diseases in most resource poor settings like Tanzania is more challenging than its well documented relative Mycobacterium tuberculosis complex (MTC) [2].

Due to their ubiquitous presence in the environment, exposure to NTM is likely common, as they can colonize the respiratory tract without causing disease such that finding NTM in respiratory secretions does not necessarily have clinical implications in all patients [3-5]. Differentiating true NTM lung infection from contamination and/or colonization is difficult; hence, the presence of acid-fast bacilli (AFB) positive by microscopy of a respiratory sample or culture poses major diagnostic challenge. Increasingly, NTM are becoming recognized as true pathogens and important causes of human infections $[6,7]$.

Information on the role, contribution and burden of NTM in aetiology of TB-like syndromes is limited in many sub-Saharan African countries endemic to TB and HIV [8-10]. Lack of rapid and accurate methods to diagnose AFB positive pulmonary infections due to NTM results in misdiagnosis and mismanagement of pulmonary TB in such settings. Correct and timely identification of NTM is particularly urgent for both therapy and epidemiology, since infections with different mycobacterial species demand different management approaches $[11,12]$.

Tanzania is among the 22 high burden countries (HBCs) in the world with high prevalence of TB. On average, 61,500 new TB patients are notified annually [13]. Patients with AFB positive sputum or with chest radiographic findings presumptive of active $\mathrm{TB}$, who do not respond to general antimicrobials, are generally assumed positive for TB. As a general guideline, patients are empirically treated with first line anti-TB drugs for 6 months.

Since several TB-like syndromes could also be due to NTM, inconclusive diagnosis of pulmonary TB would result in over-diagnosis of TB and hence miss-management of both TB and NTM infections.

Invention of DNA strip technology (line probe assays) based on reverse hybridization of PCR products to their complementary oligonucleotide probes has revolutionized the diagnosis of NTM. Commercial DNA strip assay kits GenoType ${ }^{\circledR}$ Mycobacterium CM/AS (Hain Life science GmbH, Nehren, Germany); GenoType ${ }^{\circledR} \mathrm{CM} / \mathrm{AS}$ for detection of common and additional NTM species have been widely and successfully used as rapid molecular tools in the diagnosis of NTM both in resource poor and developed countries. However, cross-reactivity of DNA probes between mycobacterial species has been reported, leading to incorrect diagnosis and treatment of patients $[14,15]$. Use of molecular techniques targeting the $16 \mathrm{~S}$ rRNA and $h s p 65$ genes have been useful in diagnosis and speciation of NTM, including those which are dead or uncultivable [16].

The objective of the present study was therefore to determine the frequency and diversity of NTM among TB suspects in Northeastern Tanzania using conventional phenotypic methods, GenoType ${ }^{\circledR}$ Mycobacterium $\mathrm{CM} / \mathrm{AS}$ kits and $16 \mathrm{~S}$ rRNA as well as hsp65 gene sequencing.

Our findings suggest that NTM infections may play a vital role in causing lung disease and hence impacting management of TB in endemic settings like Tanzania. Therefore, the need to consider NTM in TB control programmes in such settings is urgent.

\section{Methods}

\section{Study settings}

The study was conducted in two peripheral diagnostic centres (PDCs) of Ngamiani and Makorora. The centres serve as primary catchment for TB diagnosis in Tanga municipal and two hospitals of Muheza Designated District Hospital (MDDH) and Bombo referral hospital. Tanga is among the top 10 regions with high TB notification in Tanzania with annual TB notification cases for the entire region being about 3852 cases, and the TB prevalence of 217/100,000 and 244/100,000 in urban and rural settings respectively as per national prevalence survey, 2012 [17]. 


\section{Study design}

A cross-sectional study was carried out between November 2012 through January 2013. A total of 744 spot and morning sputum samples were collected from $372 \mathrm{~TB}$ suspected patients self-presenting at the PDCs and hospitals. All patients presenting to the diagnostic centre with any of the following symptoms were included: presences of symptoms suggestive of $\mathrm{TB}$ for a period of $\geq 2$ weeks, night sweats, fatigue, unexpected loss of weight, and fever. Three sputum samples were collected from patients (one on the spot during the first visit, one early morning and another spot the following morning). Early morning sputa were stored at $-20{ }^{\circ} \mathrm{C}$ and later transported to the Mycobacteriology laboratory at the University hospital Leipzig, Germany for culture and molecular identification.

\section{Smear microscopy and culture isolation}

Direct smear microscopy using Ziehl Neelsen (ZN) or fluorescent stains were performed at the respective study sites by experienced laboratory technicians and the results recorded in accordance to the WHO/IUTLD and National Tuberculosis and Leprosy Programme (NTLP) guidelines $[18,19]$.

In Leipzig, all the sputum specimens were processed by the standard N-acetyl-L-cysteine (NALC)-NaOH method [20]. Briefly, $10 \mathrm{ml}$ of $0.5 \% \mathrm{~N}$-acetyl-cysteine (NALC) solution was added to each sample, specimens were then incubated at room temperature on a shaker for $20 \mathrm{~min}$, followed by addition of $30 \mathrm{ml}$ of phosphate buffered saline (PBS) pH 6.8 for neutralization and subsequently centrifuged at $3000 \times g$ for $20 \mathrm{~min}$. The sediments were resuspended in $1 \mathrm{ml}$ PBS after discarding the supernatant. All the decontamination procedure followed the Deutsches Institut für Normung (DIN) recommendations for the detection of mycobacteria [21].

About 2-3 drops of resuspended specimens were inoculated on Lowenstein-Jensen (LJ), Gottsacker, and Coletsos slants (Artelt-ENCLIT GmbH, Germany) supplemented with antibiotics (Polymyxin B (200,000 IU/ liter), Amphotericin B (10 mg/liter), Carbenicillin (50 mg/liter), and Trimethoprim (10 mg/liter) (PACT). Cultures were incubated for 8 weeks at $37{ }^{\circ} \mathrm{C}$ and read weekly.

Examination and reporting of smear microscopy was performed by fluorescent microscopy. Subsequently, $0.5 \mathrm{ml}$ of each specimen was inoculated into BacT/Alert bottles supplemented with antibiotics PACT and incubated in an automated BacT/Alert 3D System (Biomérieux, Marcy l'Etoile, France) liquid culture system for 8 weeks. Culture not showing any growth after 8 weeks of incubation was considered negative. Positive BacT/Alert bottles were checked for purity by plating a drop from each positive bottle onto blood agar (BA) plate to rule out false positive results due to bacterial contamination and simultaneously ZN stain was performed to confirm presence of AFB positive results.

\section{Phenotypic identification}

Slants containing pure cultures of AFB were assessed for growth rate and pigment accumulation on LJ, Gottsacker or Coletsos slants (at $30^{\circ} \mathrm{C}, 37^{\circ} \mathrm{C}$ and $45^{\circ} \mathrm{C}$ ). NTM isolates were grouped based on Runyon classification and results compared with those of molecular methods.

\section{DNA extraction}

Mycobacterial DNA was extracted from heat-inactivated AFB isolates. Briefly, bacteria suspended in $500 \mu \mathrm{l}$ sterile water or $1 \mathrm{ml}$ directly from positive BacT/Alert bottles were inactivated at $80^{\circ} \mathrm{C}$ for $20 \mathrm{~min}$, then ultra-sonicated at $35 \mathrm{kHz}$ and heated at $100{ }^{\circ} \mathrm{C}$ for $10 \mathrm{~min}$ each treatment and centrifuged at $16,100 \times g$ two times for $5 \mathrm{~min}$. The supernatant was taken as template DNA. Genomic DNA of the H37Rv strain and sterile distilled water were used as positive and negative controls respectively for all molecular procedures.

\section{Identification of NTM by GenoType ${ }^{\circledR}$ Mycobacterium CM/AS assay}

All isolates identified as NTM based on their cultural characteristics and confirmed by $\mathrm{ZN}$ staining were subjected to further definitive identification using two commercial kits, the GenoType ${ }^{\circledR}$ Mycobacterium CM for detection of common NTM. Isolates not identified by GenoType ${ }^{\circledR}$ CM assay were further tested with the GenoType $^{\circledR}$ AS assay for additional NTM. All the procedures followed manufacturer's instructions.

\section{DNA sequence analysis}

All isolates not identified to the species level by the CM/ AS assay were analyzed by $16 \mathrm{~S}$ rRNA and $h s p 65$ gene sequencing. For sequence analysis of the $16 \mathrm{~S}$ rRNA gene was done according to [22] using the primers 285 and 264 for generating the PCR product $(1037 \mathrm{bp})$ and primer 271 for sequencing. For $h s p 65$ gene sequencing, PCR was done according to [23] using the primers 21M13TB11/ M13TB12 generating a $441 \mathrm{bp}$ fragment. For sequencing, the primer M13/pUC forward was used. The primers were purchased from Jena Bioscience, Jena, Germany. The PCR products were purified for sequencing using QIAquick PCR Purification Kit or alternatively QIAquick Gel Extraction Kit according to the manufacturer's instructions. Sequencing was done by GATC Company (Konstanz, Germany). The raw data were analyzed at the FLI using the National Centre for Biotechnology Information (NCBI) BLAST software optimized for highly 
similar sequences (http://blast.ncbi.nlm.nih.gov). Strain identification was based on the BLAST hit with the highest scores combined with greatest sequence coverage and identity. Reference strains with the highest similarity score as present in the NCBI database were used as references for the similarity assessment.

\section{Data analysis}

Demographic and clinical data were cleared and analysed by SPSS version 11.5 for Windows (SPSS Inc., Chicago, IL) software package. Binary regression model was used to analyse the predictors of NTM isolation. One-way analysis of variance (ANOVA) was used to determine trend analysis across ordered groups. $P$ value $<0.05$ was considered statistically significant. GenoType ${ }^{\circledR}$ Mycobacterium CM/AS assay results were interpreted based on manufacturers instruction.

\section{Ethical clearance}

The protocol for this study was reviewed and approved by the Ethical Committee of the National Institute for Medical Research (NIMR), Dar es Salaam, Tanzania. Written informed consent was obtained from the patients or relatives of the patients, where the patients could not read and write.

\section{Results}

A total of 744 sputum samples were collected from 372 TB suspects who self-presented at two PDCs and two hospitals in Tanga, northeastern, Tanzania. The proportion of males 196 (52.7 \%) was higher than that of female $176(47.3 \%)$. The median age of the patients was 40 years (range $7-88$ years).

\section{Demographic characteristics of patients and risk factors associated with NTM}

Demographic data and risk factors associated with NTM infections are shown in (Tables 1,2). The overall frequency of the patients with NTM in the study was $9.7 \%$; HIV positivity was found to be associated with NTM infection among the factors analysed, with a statistical significance of (OR 3.86, 95 \% CI [1.79-8.3], $P<0.001$ ). There was no association between NTM and other factors analysed.

\section{Culture Results}

Of the 372 patients, positive mycobacterial cultures were obtained in 121 (32.5\%) patients and among these 36 (9.7\%) patients harboured NTM, which are subject of this paper. From each patient three sputum samples were analysed for NTM growth. In total, 101 sputum samples were positive for NTM by culture. In this regard, 29 patients $(80.6 \%)$ were positive for NTM growth in all three samples and seven patients (19.4\%) were positive for NTM only in two out of the three samples. NTM without any other coinfections were detected in $21(58.3 \%)$ patients. NTM coinfection with HIV was found in $11(30.6 \%)$ patients, with MTBC in three $(8.3 \%)$ patients and NTM with both HIV and MTBC coinfections in one $(2.8 \%)$ patient. One patient was simultaneously positive for NTM plus Nocardia spp. (data not shown) (Table 3). None of the patients had mixed NTM infections.

Of the 121 patients, 81 (66.9\%) patients had positive smear microscopy for AFB and 40 (33.1\%) patients were smear negative at the laboratory in Leipzig. On the other hand, of those 121 patients with positive culture results, $64(52.9 \%)$ patients had positive smear microscopy for AFB and 56 (46.3\%) patients had negative smear microscopy for AFB at local PDCs/hospitals, whereas only one $(0.8 \%)$ patient had smear positive AFB at local PDCs/ hospitals but negative smear microscopy and culture in Leipzig.

\section{Phenotypic identification of the NTM}

Based on their growth characteristics and pigment production, the isolates were grouped into different Runyon groups [24]. Eighteen isolates were classified as scotochromogenic (Runyon II), 13 as nonphotochromogenic (III), 4 as photochromogenic (Runyon I) and 1 as rapid growing mycobacteria (Runyon IV). The results were comparable to the molecular detection by Hain kit results (Table 4).

\section{Distribution of mycobacterial isolates by site}

Results of genotyping using GenoType ${ }^{\circledR}$ MTBC for the MTC and GenoType ${ }^{\circledR}$ Mycobacterium CM/AS for NTM isolates at each site showed that the prevalence of $M$. tuberculosis alone were 10.4, 22.7, 24.2 and $26.9 \%$ at Makorora HC, Ngamiani HC, Bombo RH and MDDH respectively. The prevalence of NTM alone were 10.4, 11.0, 1.6 and $8.2 \%$ at Makorora HC, Ngamiani HC, Bombo RH and MDDH respectively (Table 1).

\section{Identification of NTM isolates GenoType ${ }^{\circledR}$ Mycobacterium CM/AS}

Identification of NTM isolates to species level by GenoType $^{\circledR}$ Mycobacterium CM/AS kits was achieved in 28 (77.8 \%) isolates with GenoType ${ }^{\circledR}$ Mycobacterium CM identifying $23(63.9 \%)$ of the isolates and GenoType ${ }^{\circledR}$ Mycobacterium AS identifying 5 (13.9 \%) isolates. On the other hand, eight (22.2\%) out of 36 isolates could not be identified by either kit. M. gordonae and M. interjectum were the most frequently identified with 6 (16.7 \%) isolates each, followed by $M$. intracellulare 4 (11.1\%), M. scrofulaceum 3 (8.3 \%), M. avium spp. 2 (5.5 \%), M. 
Table 1 Demographic characteristics and laboratory findings of the patients with NTM infections stratified by site

\begin{tabular}{|c|c|c|c|c|c|}
\hline $\begin{array}{l}\text { Demographic and risk } \\
\text { factors }\end{array}$ & $\begin{array}{l}\text { Makorora HC } \\
n=48(\%)\end{array}$ & $\begin{array}{l}\text { Ngamian } \mathrm{HC} \\
\mathrm{n}=128(\%)\end{array}$ & $\begin{array}{l}\text { Bombo RH } \\
n=62(\%)\end{array}$ & $\begin{array}{l}\text { Muheza DDH } \\
\mathrm{n}=134(\%)\end{array}$ & $\begin{array}{l}\text { Total } \\
\mathrm{n}=372\end{array}$ \\
\hline \multicolumn{6}{|l|}{ Gender } \\
\hline Female & $20(41.7)$ & $56(43.7)$ & $40(64.5)$ & $60(44.8)$ & 176 \\
\hline Male & $28(58.3)$ & $72(56.3)$ & $22(35.5)$ & $74(55.2)$ & 196 \\
\hline Age: Mean (SD) & $45.1(18.9)$ & $39.4(17.6)$ & $38.3(15.6)$ & $42.9(16.9)$ & \\
\hline \multicolumn{6}{|l|}{ Age groups (years) } \\
\hline$<20$ & $1(2.1)$ & $8(6.3)$ & $6(9.7)$ & $6(4.5)$ & 21 \\
\hline $20-40$ & $13(27.1)$ & $69(53.9)$ & $23(37.1)$ & $51(38.1)$ & 156 \\
\hline $40-60$ & $22(45.8)$ & $29(22.6)$ & $27(43.5)$ & $57(42.5)$ & 135 \\
\hline$>60$ & $12(25.0)$ & $22(17.2)$ & $6(9.7)$ & $20(14.9)$ & 60 \\
\hline \multicolumn{6}{|l|}{ Residence } \\
\hline Urban & 39 (81.3) & $97(75.8)$ & $43(69.4)$ & $28(20.9)$ & 207 \\
\hline Rural & $9(18.7)$ & $31(24.2)$ & 19 (30.6) & $106(79.1)$ & 165 \\
\hline \multicolumn{6}{|l|}{ Occupation } \\
\hline Peasants & $24(50.0)$ & $33(25.8)$ & $31(50.0)$ & $68(50.8)$ & 156 \\
\hline Housewife & $11(22.9)$ & $16(12.5)$ & $18(29.0)$ & $24(17.9)$ & 69 \\
\hline Business & $5(10.4)$ & $24(18.8)$ & $5(8.1)$ & $11(8.2)$ & 45 \\
\hline Others & $8(16.7)$ & $55(42.9)$ & $8(12.9)$ & $31(23.1)$ & 102 \\
\hline $\begin{array}{l}\text { Prevalence of MTBC } \\
\text { alone }\end{array}$ & $5(10.4)$ & $29(22.7)$ & $15(24.2)$ & $36(26.9)$ & 85 \\
\hline $\begin{array}{l}\text { Prevalence of NTM } \\
\text { alone }\end{array}$ & $5(10.4)$ & $14(11.0)$ & $1(1.6)$ & $11(8.2)$ & 31 \\
\hline $\begin{array}{l}\text { Prevalence of MTB } \\
\text { +NTM }\end{array}$ & 0 & $3(3.2)$ & $1(1.6)$ & $1(0.7)$ & 5 \\
\hline \multicolumn{6}{|l|}{ Concurrent conditions } \\
\hline HIV + ve & $12(25.0)$ & 14 (10.9) & $13(30.0)$ & $14(10.4)$ & 53 \\
\hline HIV - ve & 7 (14.6) & $87(68.0)$ & $1(1.6)$ & 19 (14.2) & 114 \\
\hline Unknown & $29(60.4)$ & 27 (21.1) & $48(77.4)$ & $101(75.4)$ & 205 \\
\hline \multicolumn{6}{|l|}{ Previous TB } \\
\hline Yes & $9(18.7)$ & $33(25.8)$ & $1(1.6)$ & $16(11.9)$ & 59 \\
\hline No & 39 (81.3) & $95(74.2)$ & 61 (98.4) & $118(88.1)$ & 313 \\
\hline
\end{tabular}

HC health Centre, MDDH Muheza Designated District Hospital, MTBC M. tuberculosis complex, NTM nontuberculous mycobacterium

Table 2 Risk factors associated with NTM infection among suspected TB patients attending PDCs/hospitals in north-eastern, Tanzania from November 2012 to January 2013

\begin{tabular}{llll}
\hline & OR & $\mathbf{9 5} \% \mathbf{C l}$ & P value \\
\hline Gender & 0.83 & $0.42-1.66$ & 0.6 \\
Age & 1.02 & $0.52-2.04$ & 0.95 \\
Location & 0.96 & $0.48-1.9$ & 0.9 \\
Occupation & 0.95 & $0.43-2.1$ & 0.8 \\
HIV positive & 3.86 & $1.79-8.3$ & $0.001^{*}$ \\
Previous TB & 0.84 & $0.31-2.26$ & 0.7
\end{tabular}

OR odd ratio, $\mathrm{Cl}$ confidence interval

* $P$ value is statistically significant at $P<0.05$
Table 3 Comorbidity of NTM with either M.tb and or HIV among individuals with NTMs

\begin{tabular}{ll}
\hline Type of infection & No. of individuals (\%) \\
\hline NTM alone & $21(58.3 \%)$ \\
HIV + NTM & $11(30.6 \%)$ \\
NTM + M.tb & $3(8.3 \%)$ \\
HIV + NTM + M.tb & $1(2.8 \%)$ \\
Total & 36 \\
\hline
\end{tabular}

fortuitum 2 (5.5\%), M. kansasii 1 (2.8\%), M. lentiflavum 1 (2.8 \%), M. simiae 1 (2.8 \%), M. celatum 1 (2.8 \%) and M. marinum 1 (2.8 \%) (Table 4). 
Table 4 Species distribution of the NTM isolated from PDCs/hospitals in northeastern Tanzania based on Runyon grouping and GenoType ${ }^{\circledR}$ Mycobacterium CM/ AS

\begin{tabular}{llll}
\hline $\begin{array}{l}\text { Prevalence of NTM } \\
\text { infection }\end{array}$ & Runyon group & $\mathbf{n = 3 6}(\mathbf{\%})$ & Assay \\
\hline M. gordonae & || & $6(16.7)$ & GenoType CM \\
M. interjectum & II & $6(16.7)$ & GenoType CM \\
M. intracellulare & III & $4(11.1)$ & GenoType CM \\
M. scrofulaceum & II & $3(8.3)$ & GenoType CM \\
M. avium spp. & III & $2(5.5)$ & GenoType CM \\
M. fortuitum & II & $2(5.5)$ & GenoType CM \\
M. kansasii & I & $1(2.8)$ & GenoType AS \\
M. lentiflavum & II & $1(2.8)$ & GenoType AS \\
M. simiae & I & $1(2.8)$ & GenoType AS \\
M. celatum & III & $1(2.8)$ & GenoType AS \\
M. marinum & I & $1(2.8)$ & GenoType AS \\
NTM not identified & & $8(22.2)$ & \\
\hline
\end{tabular}

\section{$16 \mathrm{~S}$ rRNA gene and $h s p 65$ gene sequencing}

Eight isolates not previously identified by the GenoType ${ }^{\circledR}$ Mycobacterium CM/AS kits were analysed by $16 \mathrm{~S}$ rRNA gene sequencing and additionally by $h s p 65$ gene sequencing. Three of eight species yielded comparable results with both genes while five $h s p 65$ analyses gave results different from $16 \mathrm{~S}$ rRNA gene sequencing.

16S rRNA gene sequencing for the eight isolates yielded $M$. kumamotonense $(\mathrm{n}=2)$, M. intracelullarel kansasii, $M$. intermedium/triplex, $M$. acapulcensis/favenscens, $M$. stomatepiae, $M$. colombiense and $M$. terrae complex $(\mathrm{n}=1)$. The results with the respective lengths of the sequenced DNA stretches are shown in (Table 5).

\section{Discussion}

While the epidemiology of TB is well documented, the prevalence and epidemiology of NTM in Tanzania is largely unravelled [25]. NTM pulmonary infections are increasingly reported because of increased populations at-risk due to HIV infection, old age, other immunosuppressive conditions, increased awareness and improved diagnostic facilities especially in developed countries [26, 27].

In Tanzania, the existing supposition is that most individuals presenting with pulmonary symptoms reflecting mycobacterial diseases are infected with MTC. Chances that NTM are missed during diagnosis is to a great extent attributed to poor diagnostic capabilities for culture and identification of NTM, endemic nature of MTC, overburden by diseases like malaria and HIV. Furthermore, lack of awareness among public health personnel and lack of standardized or accepted criteria to properly define and report NTM have all resulted to less attention on the NTM infections.

In this study, the overall frequency of patients with NTM detected by Hain kits among pulmonary TB suspects population was $9.7 \%$. We identified $M$. gordonae and $M$. interjectum with $6(16.7 \%)$ isolates each accounting for about one-third of all NTM isolates, $M$. intracelullare 4 (11.1\%), $M$. avium spp. and $M$. fortuitum 2 (5.5\%), $M$. kansasii, M. lentiflavum, M. simiae, M. celatum, $M$. marinum 1 (2.8 \%) isolate each. Additionally, eight isolates, which gave no signal with GenoType ${ }^{\circledR}$ Mycobacterium CM/AS kits were identified by $16 \mathrm{~S}$ rRNA gene sequencing. These isolates were assigned to the species $M$. kumamotonense (2), M. intracellulare/kansaii (1), $M$. intermedium/M. triplex (1), M. acapulcensis/M. flavescens

Table 5 NTM species identified based on 16S rRNA gene and $h s p 65$ gene sequencing

\begin{tabular}{|c|c|c|c|c|}
\hline Strain ID & 16S rRNA gene sequencing & Identity/sequence length (bp) & hsp65 gene sequencing & Identity/sequence length (bp) \\
\hline TZ095 & M. kumamotonense & $558 / 559$ & M. kumamononense & $357 / 357$ \\
\hline \multirow[t]{2}{*}{ TZ141 } & M. intracellulare & $922 / 928$ & M. scrofulaceum & $343 / 359$ \\
\hline & M. kansasii & $924 / 928$ & M. avium complex & $343 / 360$ \\
\hline \multirow[t]{2}{*}{ TZ145 } & M. intermedium & $902 / 916$ & M. avium complex & $300 / 315$ \\
\hline & M. triplex & $896 / 916$ & & \\
\hline \multirow[t]{2}{*}{ TZ147 } & M. acapulcensis & $918 / 918$ & M. flavescens & $369 / 372$ \\
\hline & M. flavescens & $912 / 919$ & M. novocastrense & $368 / 372$ \\
\hline \multirow[t]{2}{*}{ TZ149 } & M. kumamotonense & $928 / 928$ & M. kumamotonense & $356 / 357$ \\
\hline & & & M. hiberniae & $382 / 384$ \\
\hline $\mathrm{TZ217}$ & M. stomatepiae & $570 / 570$ & M. lentiflavum & $362 / 372$ \\
\hline \multirow[t]{2}{*}{ TZ224 } & M. colombiense & $928 / 928$ & M. colombiense & $378 / 385$ \\
\hline & & & M. avium complex & $376 / 385$ \\
\hline \multirow[t]{3}{*}{ TZ294 } & M. terrae complex & $923 / 931$ & M. kumamotonense & $368 / 384$ \\
\hline & & & M.terrae & $364 / 384$ \\
\hline & & & M. hiberniae & $363 / 384$ \\
\hline
\end{tabular}


(1), M. stomatepiae (1), M. colombiense (1) and M. terrae (1). Additionally, $h s p 65$ gene sequencing was conducted if the $16 \mathrm{~S}$ rRNA sequences were not discriminatory in order to confirm especially the ambiguous species assignments. However, only three of eight isolates both genes indicated the same species, for five isolates discordant results were achieved by sequencing both genes (Table 5). Sequencing of different genes used for bacterial species identification may yield inconsistent results. The problem is even more complicated with mycobacteria which are characterized by interspecies similarity clearly higher than in other bacteria $[28,29]$. These results emphasise the difficulties of species identification for NTM. Therefore, it is of great importance to standardize the methods in order to generate comparable results between different laboratories, countries and continents.

M. kumamotonense, M. acapulcensis M. novocastrense, M. stomatepiae, and M. hiberniae determined by either $16 \mathrm{~S}$ rRNA or $h s p 65$ in this study (Table 5) have been reported elsewhere in the world. Some of which have been associated with human diseases and others isolated from the environment [30-33]. To the best of our understanding, these species have not previously reported in Tanzania.

Our findings are in agreement with findings from other studies in Tanzania and Africa which indicated increasing prevalence of NTM $[9,34,35]$. Whether there exist geographic variations in the diversity of NTM in Tanzania is not clear since this study focused only on patients residing in a more or less similar geographic location along the northeastern coast of Tanzania.

Understanding the distribution and clinical impact of NTM is of public health significance, as it addresses concerns of over diagnosis of tuberculosis and potential under treatment of NTM infections. As reported previously [35], there exist quite diverse species of NTM among humans, livestock and wildlife [36]; this therefore stresses need to investigate the distribution and clinical impact of different NTM species in Tanzania.

Analysis of the predictors of NTM infection in this study shows lack of association among gender, age, area of residence and occupation in patients diagnosed with NTM. However, need to study NTM infections in TB endemic settings like Tanzania through a larger cohort and evaluation of their impact on TB disease is particularly urgent. Though in the present study we did not perform drug susceptibility testing for the isolated NTM, such patients may erroneously regarded as having MDR isolates.

Immunocompromised individuals due to HIV/AIDS are at a high risk of NTM infections, with $M$. intracellulare, and M. avium complex (MAC) being frequently reported [37-39].
Findings from this study show that individuals with HIV positive status had a varying range of NTM infections and HIV was an important predictor of NTM detection (OR 3.86, $95 \%$ CI [1.79-8.3], p < 0.001). The identified NTM included M. scrofulaceum (2), M. avium spp. (2), M. gordonae (2), M. intracelullare (1), M. lentiflavum (1), M. celatum (1) and M. interjectum (1). Two of the isolates from HIV positive cases, not identified by the Hain kits, were found to belong to M. kumamotonense and $M$. intracellulare by $16 \mathrm{~S}$ rRNA sequencing.

MAC and rarely identified species of $M$. lentiflavum and $M$. sherrisii were reported among HIV positive patients with pulmonary disease in Zambia and Tanzania $[9,34,40]$. M. sherrisii which was found to be commonly associated with HIV individuals in northern Tanzania [34], was not detected in this patient population. $M$. celatum commonly isolated from human respiratory tract specimens is also known to be pathogenic to HIV patients and sometimes non-immunocompromised patients [41], whereas, M. gordonae a common contaminant of water supply, soil, casual resident in human sputum and gastric lavage specimens is rarely (e.g. AIDS) if ever implicated in disease processes [41].

NTM co-infections with $M$. tuberculosis disease are rarely diagnosed owing to overlapping clinical manifestations [10]. Our results show that five (1.3\%) individuals had both $M$. tuberculosis and NTM which included $M$. scrofulaceum (2), M. interjectum (1), M. gordonae (1) and one isolate not identified by Hain kits was identified as $M$. kumamotonense by $16 \mathrm{~S}$ rRNA sequencing. Although it may be assumed that patients with such co-infections in many cases manifest symptoms mainly due to $M$. tuberculosis, the role of such co-infections underscore the need for further research to determine their contribution in the disease pathogenesis, severity and progression.

NTMs pose a major challenge for TB treatment programmes since such patients are managed mainly on the basis of smear microscopy which is not suitable to differentiate between MTC and NTM, but also major drawbacks lie on limited sensitivity and specificity of symptoms and radiology [8]. Culture on the other hand, is the gold standard but is time consuming, demands use of different types of media and longer incubation for optimization of growth. Since such elaborate culture algorithms are scarce outside the reference centres, NTMs warrant a special emphasis as possible cause of disease.

Although we cannot certainly conclude whether the isolated NTM merit to be classified as cause of infection/ disease in each particular case, a mere presence of NTM in a particular case could make the decision on the diagnosis more complex. Need for public hygiene education is particularly high, since NTM are mostly found in the environment (water, soil). If people exert better hygiene 
management in their homes and food preparation, animal keeping, water boiling before drinking and so on, the risk of being infected would decrease, especially for persons at risk such as children, elderly, and immunocompromised individuals.

\section{Limitations}

A number of factors could have limited our findings. Firstly, lack of preliminary laboratory data on the chronic patients presented limited us from determining whether they had been infected only by an NTM or they primarily had coinfection with $M$. tuberculosis. Secondly, lack of follow up limits the capacity to establish patients' outcomes especially with NTM disease in many resource poor settings. Moreover, the true prevalence of NTM can only be assessed through a wider epidemiological study. These findings were communicated to the Medical Research Coordinating Committee where National Tuberculosis Control Program is represented. However, we are not sure if NTLP guided starting of appropriate treatment for NTM since there are no clear national guidelines for management of NTMs. This makes these findings very important as they may serve as baseline data for the NTLP to develop guidelines for management of NTMs.

In conclusion, our findings suggest that there is a diverse range of NTM infections, which may play a vital role in causing lung disease and impact the management of TB in TB-endemic settings leading to misdiagnosis and inappropriate treatment of MDR cases particularly the clinically "chronic cases". This highlights the need to consider NTM when treating patients with putative TB treatment failures. Moreover, fundamental information that meets ATS/IDSA diagnostic criteria for diagnosis of pulmonary NTM is needed to improve the understanding of NTM disease. There is an urgent need of formulating standardized criteria for defining and reporting NTM infections. We recommend that laboratory diagnosis of NTM infections be centralized by strengthening and setting up quality national and regional infrastructure.

\section{Authors' contributions}

ASH and BK participated in designing the study. ASH collected the samples, conducted the experiments, performed data analysis and drafted the manuscript, SGMM participated in data analysis and proof read the manuscript. ACR participated in proof reading the manuscript. IM performed sequence analyses and proofread the manuscript. BK participated in proof reading the manuscript and coordinated the study. All authors read and approved the final manuscript.

\section{Author details}

${ }^{1}$ Institute of Medical Microbiology and Epidemiology of Infectious Diseases, University of Leipzig, Liebigstrasse 21, 04103 Leipzig, Germany. ${ }^{2}$ Sokoine University of Agriculture, Morogoro, Tanzania. ${ }^{3}$ Muhimbili Centre, National Institute for Medical Research (NIMR), Dar es Salaam, Tanzania. ${ }^{4}$ Federal Research for Animal Health, Friedrich Loeffler Institut, Jena, Germany.

\section{Acknowledgements}

We wish to extend our heartfelt gratitude and appreciation to Tanga Regional Medical Officer, District Medical Officers, Municipal and District TB co-ordinators in Muheza and Tanga. Our gratitude also goes to all medical officers in charge and laboratory staff of the Ngamiani and Makorora health centres, Bombo and Muheza Designated District hospitals, Ms. Elizabeth Kraftschek, Gesine Kauth, Dr. Joerg Beer for their technical support and Ms. Tigest Alemu for statistical analysis. We acknowledge Ms. Catherine Sweeney-Read for editing the manuscript. This study was carried out with financial support from the Institute of Medical Microbiology and Epidemiology of Infectious Diseases, University Hospital Leipzig, Germany and the German Academic Exchange Service (DAAD).

\section{Competing interests}

The authors declare that they have no competing interest.

Received: 27 August 2014 Accepted: 9 February 2016

Published online: 17 February 2016

\section{References}

1. Kendall B, Winthrop K. Update on the epidemiology of pulmonary nontuberculous mycobacterial infections. Semin Respir Crit Care Med. 2013;34:087-94

2. Marras TK, Daley CL. Epidemiology of human pulmonary infection with nontuberculous mycobacteria. Clin Chest Med. 2002;23:553-67.

3. Olusoji D, Osman E, Adebiyi P, Mourad G, Declarcq E, Bakare R. Nontuberculosis mycobacteria isolates among new and previously treated pulmonary tuberculosis patients in Nigeria. Asian Pac J Trop Dis. 2011;1(2):113-5.

4. Thomson RM. Changing epidemiology of pulmonary nontuberculous mycobacteria infections. Emerg Infect Dis. 2010;16:1576-83.

5. van Ingen J, Blaak H, de Beer J, de RodaHusman AM, van Soolingen D. Rapidly growing nontuberculous mycobacteria cultured from home tap and shower water. J Appl Environ Microbiol. 2010;76:6017-9.

6. Varghese B, Memish Z, Abuljadayel N, Al-Hakeem R, Alrabiah F, Al-Hajoj SA, Small PLC. Emergence of clinically relevant non-tuberculous mycobacterial infections in Saudi Arabia. PLoS Negl Trop Dis. 2013;7:e2234.

7. Wu T, Lu C, Hsin-Chih L. Current situations on identification of nontuberculous mycobacteria. J Biomed Lab Sci. 2009;21:1-5.

8. Maiga M, Siddiqui S, Diallo S, Diarra B, Traoré B, Shea YR, Zelazny AM, Dembele D, Bindongo PP, Goita D, Kassambara H, Hammond AS, Polis MA, Tounkara A, Hozbor DF. Failure to recognize nontuberculous mycobacteria leads to misdiagnosis of chronic pulmonary tuberculosis. PLoS One. 2012;7:1-7.

9. Buijtels PC, van der Sande MA, de Graaff CS, Parkinson S, Verbrugh HA, Petit PL, van Soolingen D. Nontuberculous mycobacteria, Zambia. Emerg Infect Dis. 2009;15:242-9.

10. Gopinath K, Singh S, Phillips RO. Non-tuberculous mycobacteria in TBendemic countries: are we neglecting the danger? PLoS Negl Trop Dis. 2010;4:e615.

11. Griffith DE, Aksamit T, Brown-Elliott BA, Catanzaro A, Daley C, Gordin F, Holland SM, Horsburgh R, Huitt G, lademarco MF, Iseman M, Olivier K, Ruoss S, von Reyn CF, Wallace RJ, Winthrop K. An official ATS/IDSA statement: diagnosis, treatment, and prevention of nontuberculous mycobacterial diseases. Am J Respir Crit Care Med. 2007;175:367-416.

12. Heifets L. Mycobacterial infections caused by nontuberculous mycobacteria. Semin Respir Crit Care Med. 2004;25:283-95.

13. WHO: Global tuberculosis control: surveillance, planning, financing. Geneva: World Health Organization; 2007.

14. Butler WR, O'Connor SP, Yarkus MA, Gross WM. Cross-reactivity of genetic probe for detection of Mycobacterium tuberculosis with newly described species Mycobacterium celatum. J Clin Microbiol. 1994;32:536-8.

15. Lefmann M, Moter A, Schweickert B, Gobel UB. Misidentification of Mycobacterium leprae as Mycobacterium intracellulare by the COBAS AMPLICOR M. intracellulare test. J Clin Microbiol. 2005;43:1928-9.

16. Covert TC, Rodgers MR, Reyes AL, StelmaJr GN. Occurrence of nontuberculous mycobacteria in environmental samples. J Appl Environ Microbiol. 1999;65:2492-6. 
17. NTLP: The First National Tuberculosis Prevalence Survey in the United Republic of Tanzania Final Report 2013.

18. NTLP: Manual of the National Tuberculosis and Leprosy Programme in Tanzania. 5th edn. Dar es Salaam: NTLP; 2006.

19. WHO/IUATLD. Revised international definitions in tuberculosis control. Int J Tuberc Lung Dis. 2001;5:213-5.

20. Kent PT, Kubica GP. Public Health Mycobacteriology: a guide for the level III laboratory: Atlanta, GA, USA. Dept. of Health and Human Services, Public Health Service, Centers for Disease Control;1985.

21. Medical Microbiology diagnosis of tuberculosis. Part 32: Detection of mycobacteria by microscopic methods: DIN 58943-32 DIN; 1996.

22. Philip K, Böttger EC. Species identification of mycobacteria using rDNA sequencing. In: Totowa NJ, editor. Methods in Molecular Biology. New York: Human Press Inc; 1998.

23. Ringuet H, Akoua-Koffi C, Honore S, Varnerot A, Vincent V, Berche P, Gaillard JL, Pierre-Audigier CJ. hsp65 Sequencing for identification of rapidly growing mycobacteria. J Clin Microbiol. 1999;37:852-7.

24. Timpe A, Runyon EH. The relationship of "Atypical" acid-fast bacteria to human disease: a preliminary report. J Lab Clin Med. 1954;44:202-9.

25. Mfinanga SG, Morkve O, Kazwala RR, Cleavaland S, Sharp MJ, Kunda J, Nilsen R. Mycobacterial adenitis. Role of Mycobacterium bovis, non-tuberculous mycobacteria, HIV infection, and risk factors in Arusha, Tanzania. East Afr Med J. 2004;81:171-8.

26. Hatta M, Sultan AR, Tandirogang N, Yadi M. Detection and identification of mycobacteria in sputum from suspected tuberculosis patients. BMC Res Notes. 2010;3:1-6.

27. Arend SM, van Soolingen D, Ottenhoff TH. Diagnosis and treatment of lung infection with nontuberculous mycobacteria. Curr Opin Pulm Med. 2009;15:201-8.

28. Devulder G, de Montclos PM, Flandrois JP. A multigene approach to phylogenetic analysis using the genus Mycobacterium as a model. Int J Syst Evol Microbiol. 2005;55:293-302.

29. Tortoli E. Phylogeny of the genus Mycobacterium: many doubts, few certainties. Infect Genet Evol. 2012;12:827-31.

30. Masaki T, Ohkusu K, Hata H, Fujiwara N, lihara H, Yamada-Noda M, Nhung PH, Hayashi M, Asano Y, Kawamura Y, Ezaki T. Mycobacterium kumamotonense Sp. Nov. Recovered from clinical specimen and the first isolation report of Mycobacterium arupense in Japan: novel slowly growing, nonchromogenic clinical isolates related to Mycobacterium terrae complex. Microbiol Immunol. 2006;50:889-97.

31. Allen DM, Chng HH. Disseminated Mycobacterium flavescens in a probable case of chronic granulomatous disease. J Infect. 1993;26:83-6.

32. Fusco AdC, Fedrizzi T, Lopes ML, Pecorari M, Oliveira WdC, Giacobazzi E, da Costa JB, de Sanctis V, Batista KL, Bertorelli R, Grottola A, Fabio A, Mariottini A, Ferretti P, di Leva F, Fregni GS, Tagliazucchi S, Rumpianesi F, Jousson O, Segata N, Tortoli E. Characterization of 17 strains belonging to the Mycobacterium simiae complex and description of Mycobacterium paraense sp. nov. Int J Syst Evol Microbiol. 2015;65:656-62.

33. Pourahmad F, Cervellione F, Thompson K, Taggart J, Adams A, Richards R. Mycobacterium stomatepiae sp. nov, a slowly growing, non-chromogenic species isolated from fish. Int J Syst Evol Microbiol. 2008;58:2821-7.

34. Crump JA, van Ingen J, Morrissey AB, Boeree MJ, Mavura DR, Swai B, Thielman NM, Bartlett JA, Grossman H, Maro VP, van Soolingen D. Invasive disease caused by nontuberculous mycobacteria, Tanzania. Emerg Infect Dis. 2009;15:53-5.

35. Katale BZ, Mbugi EV, Botha L, Keyyu JD, Kendall S, Dockrell HM, Michel AL, Kazwala RR, Rweyemamu MM, Helden PV, Matee MI. Species diversity of non-tuberculous mycobacteria isolated from humans, livestock and wildlife in the Serengeti ecosystem, Tanzania. BMC Infect Dis. 2014;14:1-8.

36. Mwakapuja RS, Makondo ZE, Malakalinga J, Bryssinckx W, Mdegela RH, Moser I, Kazwala RR, Tanner M. Prevalence and significant geospatial clusters of bovine tuberculosis infection at livestock-wildlife interface ecosystem in Eastern Tanzania. Trop Anim Health Prod. 2013;45:1223-30.

37. Karakousis PC, Moore RD, Chaisson RE. Mycobacterium avium complex in patients with HIV infection in the era of highly active antiretroviral therapy. Lancet Infect Dis. 2004:4:557-65.

38. Katoch VM. Infections due to nontuberculous mycobacteria (NTM). Indian J Med Res. 2004;120(4):290-304.

39. Lawn SD, Bekker L, Miller RF. Immune reconstitution disease associated with mycobacterial infections in HIV-infected individuals receiving antiretrovirals. Lancet Infect Dis. 2005:5:361-73.

40. Buijtels PCAM, van der Sande MAB, Parkinson S, Verbrugh HA, Petit PLC, van Soolingen D. Isolation of non-tuberculous mycobacteria at three rural settings in Zambia; a pilot study. Clin Microbiol Infect. 2010;16:1142-8.

41. Dostal S, Richter E, Harmsen D. Concise guide to mycobacteria and their molecular differentiation. 1st ed. Würzburg: Ridom Press; 2003.

\section{Submit your next manuscript to BioMed Central and we will help you at every step:}

- We accept pre-submission inquiries

- Our selector tool helps you to find the most relevant journal

- We provide round the clock customer support

- Convenient online submission

- Thorough peer review

- Inclusion in PubMed and all major indexing services

- Maximum visibility for your research

Submit your manuscript at www.biomedcentral.com/submit
() Biomed Central 